\title{
Preface to the Tenth Anniversary Edition
}

Well, I guess I asked for it. I just wanted to know what had changed between men and women in the previous decade in Colonia Santo Domingo, on the south side of Mexico City, since the first edition of this book was published in I996, and my old friends, Héctor and Norma, had some rather pointed comments to share. During a visit in late 2005 , they told tales of adolescent romance and the penalty of ending relationships with girlfriends that Norma's son, Miguelito, then seventeen years old, had suffered at the hands of the jilted girls. It seemed Miguelito had attracted a series of passionate young women, but that each one was nuttier than the next. After he broke things off with an especially infatuated girlfriend, the family awoke one day to find graffiti spray-painted on their front door:

GODDAMNED JERK MIGUEL

SON OF YOUR GODDAMNED MOTHER . . . 1

As to why girls were writing nasty stuff on walls, Héctor insisted that changing standards more broadly in society were unfortunately responsible.

"Because morality has been relaxed. They used to tell girls to behave themselves, be serious, almost inaccessible."

Norma added, "Women are more outrageous now."

"Yeah?" I said, looking somewhat skeptical.

"I'd say so," Norma persisted. "Because of schooling. And because of women's liberation."

"Yes!" Héctor heartily agreed. 
In this preface to the new edition, I briefly update the lives and loves of my friends and neighbors in and around Huehuetzin Street in the neighborhood of Colonia Santo Domingo, Mexico City, and describe the impact on them of some of the political and economic upheavals that have occurred in the barrios populares over these past ten years. Ethnographies like the one that follows may be read like novels, in the sense that by the end you often feel that you have come to know the key protagonists in the dramas depicted within. Perhaps that is why since the book appeared in 1996 some people who have read The Meanings of Macho have asked me what has happened to Gabriel, Angela, Marcos, Doña Fili, and Liliana. One of the numerous differences between novels and ethnographies, however, is the fact that I did not choose who among the cast of characters would subsequently die, or have a child, or get divorced, or move away, or settle down, or lose and then land a good job. If you would like to keep some mystery to the stories that follow, you might want to skip this preface until you have read the rest of the book.

In some ways, the core theme of The Meanings of Macho is change, in individuals, families, and society more broadly. In particular, I explore how gender relations and identities in one former squatter settlement are not necessarily as cruel as the macho stereotypes would lead one to believe, and how in the early r 990 os various kinds of relationships between men and women, and between men themselves, were in fact undergoing remarkable transformations. One aim I had was to challenge the casual dismissal of the lives of married couples, for instance, as somehow less complicated but more oppressive in Mexico than in other contemporary societies. I did this by focusing on male gender identities and relations-even now, surprisingly underexamined in academic literature-while always trying to keep women's experiences and opinions central to the understanding I developed about men.

Where taken-for-granted notions of a universal Mexican man had prevailed, I chose instead to populate this book with a diverse array of different "kinds" of men, and to show how sometimes the notion of the macho man crossed over to and other times corresponded to other cultural attributes like class, ethnicity, age, and education. Most of all, I tried to document change: changing social consciousness (contradictory as it often proved), changing relationships between men and women, changing meanings, beliefs, and activities that could in some consequential sense be considered gendered. And what might be the moral of this tale? Diversity among Mexican men and masculinities? Sure, but that was the easy part; debunking flimsy stereotypes of macho men and 
submissive women is evidente to anyone who bothers to seriously consider the matter.

One question that haunted me in all aspects of conducting and writing up this study concerned the casual attribution of socially stigmatized ideas and behavior to "culture." I was repeatedly impressed by the popular anthropology that would attribute to culture the reason that certain beliefs and behavior were resistant to change. Culture in this version became a chief obstacle to many laudatory goals of the so-called modern family: equality for girls in education, husbands and wives sharing responsibilities for childcare and housework, and freedom from all forms of violence in the home. The archetypal example was the man who tried to defend his physically abusive behavior by explaining, "What do you expect, if you think culture matters so much? I am a product of a macho culture, and that's why I hit my wife." As an anthropologist, it was precisely what we could expect from culture that I wanted to understand. Toward that end, I landed in an enormous squatter settlement in the largest metropolitan area of the world-some twenty million inhabitants and counting. Timid and feeling clumsy about initially approaching strangers, especially about sensitive subjects like parenting, sexuality, domestic violence, and alcohol consumption, I required a patron saint to get me started. Fortunately, I found two. One was Gabriel.

Master Mechanic Gabriel, or Gabi for short, had seen me walk down the street one too many times looking for a way to strike up a conversation. Truth be told, he was the one who saved me from the ongoing pain and humiliation that had lasted more than a couple of weeks. As he stuck his head out the door of the VW bus he was repairing, he smiled and asked quizzically, "What are you doing around here?" Gabi got my foot in the door, albeit of a pretty beat-up van.

It is still rare that anyone from outside the neighborhood except relatives and deliverymen visits Santo Domingo. The colonia is simply not on the tourist maps, although Héctor did once show some North American academics around, who wanted to look more closely at a Mexico City slum. But I was fortunate. With Michelle, my wife, who was learning Spanish and looking for volunteer activities with public health programs for women, and Liliana, our infant daughter, who was only seven weeks old when we arrived in Mexico City, I found myself plopped down in Santo Domingo to live and learn for a year. And as much as I became an itinerant spectator, eyewitness, and chronicler of Colonia Santo Domingo over the next fifteen years, for those in the neighbor- 
hood who know me best I am just as much regarded as Liliana's father. After all, she spent her first year of life there and is considered a native of the colonia in ways I will never be.

\section{WOMEN AND THEIR MEN}

On the intimate level of families and households, we know too little about how women and men in Mexico discuss, debate, and decide on child rearing, who will work for money outside the home, alcohol consumption, how to resolve disagreements, and sexual relationships. In general scholars still lack detailed information on how changing affective relations between men and women in turn alter cultural values concerning these and other matters of daily significance.

Rather than compound the error of viewing men and women as inhabiting essentially separate worlds and explaining these through largely distinct worldviews, this study examined negotiations between women and men in one Mexico City neighborhood in order to address questions of gender differences and inequalities and expanding notions of gender and sexuality. Such an orientation later led a colleague to label me and two other students of men and masculinities as "antimasculinist" (see Gilmore 200I:I73), an appellation I happily accept if it refers to a conceptual framework in which the study of gender and sexuality is grounded by an understanding that men remain dominant in economics, politics, education, the media, and much else in societies throughout the world and that this is a problematic situation, to say the least.

I am uncomfortable with the tag of "antimasculinist" if it implies that relations between men and women in families and households, for example, are uniformly dominated by men, and that my purpose has been to uncover brutish Mexican variants. Because unless we understand the subtle cajoling, the vehement rage, and the abject frustrations of daily interactions between women and men in households throughout history and in different cultural milieus today, we will continue to analyze intimate gender relations simplistically. And until we view such everyday interactions as productive and not simply reductive sources of culture change, we will persist in underestimating intersubjectivity as a basis of socially significant conflict and collusion. The shifting moods and sentiments of men and women are indicators and also, potentially, critical catalysts imparting novel ways of understanding gender identities and relations, and, sometimes, new manners of living as women and men together in households and society. Important studies have been 
written since the early I970s, aimed at understanding women and gender inequalities in a wide range of cultural situations. There are still too few parallel gender studies of men, and The Meanings of Macho had as a central purpose to help address the problem of having ample studies in which men are the central protagonists but that treat men as if they were genderless, and few studies that truly approach men-as-men in order to emphasize their engendered and engendering qualities.

On my return visit to Colonia Santo Domingo in December 2005, I stopped by the house on Huehuetzin Street of my close friends Marcos and Delia and we talked, as we had so often, of changes in their lives, including in their marriage. That particular afternoon, we discussed how Marcos was still not drinking alcohol. A couple of years earlier, he and Delia had come to the conclusion that he had become an alcoholic and was going to kill himself or someone else if his drinking continued. His decision to join the ranks of the abstemious was one they made jointly, just as they had managed, together, to change another aspect of Marcos's behavior, his violent proclivities, many years before (see chapter 8). Mexican men who drink too much alcohol and are prone to physically violent outbursts - this is the stuff of pulp social science. In The Meanings of Macho my intention was instead to identify the intricate and intimate routes through which actual men and women, together, have addressed, and if they were lucky, resolved, "typical male maladies" like alcoholism and domestic violence.

Among the noteworthy changes that occurred since I first moved onto Huehuetzin Street in the early I 990 s were several deaths. These included Enrique, the invalid son of the Señora whose apartment we rented, and whose multiple illnesses everyone said finally took him to a better place; Juan, the son of my neighbor who took me once to a cock fight, who died in a liquor store holdup; and Don Timo, the septuagenarian who in the same breath explained how he took care of his small children daily and how upset he was that there were more bomosexuales who had stopped being men, thus allowing me all the more to appreciate contradiction in men's viewpoints. As anywhere else, the aged, the infirm, and the innocent young disappeared from our lives in Santo Domingo, confirming Octavio Paz's (1961:54) famous quip, "Tell me how you die and I will tell you who you are."

Some men in the colonia had gotten divorced in the decade since I996, including Gabriel, Valfre, Alejandro, and, finally, me as well. Valfre continued to visit his two children on weekends, and all reports were that everyone was getting along pretty well. Gabriel saw his children, already 
grown, when he visited them in Aguascalientes and Guanajuato, where they had moved. Alejandro and Lupita never had children together. When I returned in late 2005 , I told people of the changes and challenges in my own life as well. Michelle and I had finally called it quits, and the kids had begun living in two homes. Yes, I assured people, Liliana and Maya seemed to be handling the changes very well. And, I added, I had fallen madly in love again. "Please send our best to Michelle," my closest friends requested. "And when are you going to bring the kids to visit? And when can we meet your new pareja?" they asked. Mainly people asked after Liliana and Maya, what the girls remembered of their time in Santo Domingo, whether Lili was still as cabroncita (bossy) as she had been as an infant and young girl. I told them she was so proud of that nickname that she used it for a time as her email password, news everyone thoroughly enjoyed.

Sharing my thoughts on my children with friends and neighbors in the neighborhood was simply part of living life together. I continue to be impressed by how much time men in Colonia Santo Domingo spend talking among themselves about their children-and to my list of excuses men can legitimately use to refuse a drink with a friend (taking antibiotics or estar jurado, see chapter 7) I would today add the following phrase I have heard more than once, "Sorry, I can't have a drink because I am taking charge of my kids and I don't want them to have to take charge of me!" From the standpoint of gender studies, even more remarkable is how much time men spend among themselves talking about women. This may seem absurd: of course men talk about women, what else is new? But let me clarify. Even when women are not physically present-when men are peering into the engine cavity of a car, when men sit on a curb nursing their beers, when men gather to listen to a shopkeeper strum his guitar and talk about the old days and what he could have and should have done with his life ... if things had only worked out differently-even when women are not in attendance, they are a constant source of reference, if not always reverence.

José Limón spoke to this issue in an intrepid revision to an earlier paper on "Carne, Carnales, and the Carnavalesque." In the first version (Limón 1989) of his ethnographic depiction of a south Texas barbeque, he spoke primarily of male camaraderie and what we would today call "homosociality"- the social bonds and spaces that men share and a term that suggests these things exist in a vacuum apart from men's relationships with women. In the revised paper (1994:I40), Limón writes of "a ritually enhanced sense of dominant masculinity" emerging dur- 
ing these carne asada barbeques, which despite women's apparent absence nevertheless carries with it "repressive consequences for women." Sometimes the comments and activities of men, when there are no women around, are all too obviously related to women's "hidden" presence: I have often been privy to the offhand remarks of the men in Santo Domingo who brag of their sexual prowess-“Boom, boom, boom!" one man described to me his alleged conquests of three women the night before in the Garibaldi nightclub district. Just as often, when men gather in groups for work or leisure, women have seemed like the missing players in our conversations, as men react and reply to their wives' and daughters' wishes and demands, albeit consoled by the knowledge that for the moment the men will get the last word.

The extent to which homosociality is seen as primordially and not just superficially referring to men spending time with other men, in male venues, conducting male activities (including sex with other men), has proved controversial for certain scholars who have examined Mexican men's sexuality. Some, like Prieur (I998:190 n. I) and González-López (2005:72, I 4I), believe I underestimated the number of men who have sex with other men, and/or the number of men who have sex with male or female prostitutes (see chapter 5 ).

In the end, I think it important to remind ourselves that what scholars who spend most of their time talking to a small number of people usually write about are stories of the lives of just these few people. The appeal to generalize from this small group is intoxicating but usually best resisted. Despite the subtitle of this book and those of others, we cannot truly claim to speak for the inhabitants of Mexico City, much less Greater Mexico as a whole-we draw not on representative samples but on those who have chosen $u s$ to reveal their inner selves and their experiences (whether invented or not is often difficult to assess). In the end, we want to find use for our stories and make them more broadly relevant. I do not wish to dismiss the different conclusions that some others have come to when they declare that "a considerable part of the male population" in Mexico City "participates in homosexual encounters" (Prieur 1998:200). Yet, depending on how one defines "considerable," I sincerely doubt as many men have sex with other men in Mexico City as this formulation implies to me. ${ }^{2}$

This is nonetheless the issue about which I remain most vexed: Have I contributed in some measure to underestimating the percentage of adult men in Mexico who have and have had sex with other men? My response today goes beyond the standard ethnographic evasion: "I just 
report what they tell me, ma'am." ${ }^{3}$ The debates as to the percentage of men in Mexico who have sex with other men, for pay or for the pleasure, involve the speculation of academics and usually remain academic, in the sense of inconsequential. However, establishing how many men have sex with other men can have immense value in determining with greater certainly, for example, the primary vectors for the transmission of AIDS. In particular, if possibly there has been an overemphasis on male same-sex sex, then we may have underestimated the dangers of heterosexual transmission of the virus, including with prostitutes. In that case, the debate would be valuable indeed.

\section{RAISED AND DASHED HOPES OF SOCIAL CHANGE}

In some respects, the two decades from 1985 to 2005 in Mexico were marked by heightened and frustrated expectations for political and economic improvement. Beginning with the presidential elections in 1988 , and culminating in 2000 with the election of Vicente Fox, a candidate who did not represent the PRI party that had held that office for over six decades, many in the neighborhood, as throughout Mexico, fervently wanted to believe something radically new and better was within reach. By December 2005, no one I know was happy with Fox, yet more than a few held out a new hope for the center-left politician Andrés Manuel López Obrador, who was running for president in the elections to be held in July 2006, and who had accomplished some significant reforms during his tenure as mayor of Mexico City from 2000 to 2005. Even with emerging support for López Obrador, however, disenchantment with voting as the sacred route to social change was evident in the comments from nearly all my friends in the colonia as the 2006 elections approached. In a subsequent ethnography, also based in Colonia Santo Domingo, The Romance of Democracy: Compliant Defiance in Contemporary Mexico (Gutmann 2002), I sought to document recent trends in popular politics regarding issues of electoral politics, migration, the North American Free Trade Agreement, and the 1994 Chiapas uprising.

After experiencing financial problems in the late I990s, Marcelo moved to Cuernavaca to open a little corner store, as it was supposed to be less expensive to live and operate a small business there. Two years after the death of his mother, Maestro Gabriel was back repairing cars at the edge of a main avenue bordering the neighborhood that he had 
abandoned earlier. He was barely able to support himself and send money to his daughter, Gabriela, who was trying to make a go of it up north manufacturing natural remedies from honey. "This natural product stuff is what everyone wants now," Gabriel confided with a smile. In 2005 , Héctor's metal workshop was, he said, barely keeping afloat; Héctor simply could not compete with Chinese imports. True enough, despite several economic crises in these two decades, there also had been bright spots: around 2000, several families I know used money from the government to add on to their houses, often by building a larger apartment over the rooms below. And despite recessionary trends, my friend Luciano was happy to report, in early 2004, that counterfeit RayBans were still available for far less money in Mexico than elsewhere.

In 2005, an ever increasing number of women in Santo Domingo were working outside the home, thereby substantially increasing household incomes. Yet, following the financial crisis and the implementation of the North American Free Trade Agreement in 1994, local industries had closed and public sector employment, such as in health care, seemed to many to be disappearing as privatization progressed. In late 2005 the United Nations reported that 60 percent of children in Mexico were living in poverty (Aviles 2005), while World Bank figures for the country as a whole in 2004 showed a full 20 percent of the population living in conditions of "extreme poverty" and over 50 percent in moderate poverty (see Wolfensohn 2004).

When I arrived in Santo Domingo for the first time, in I99I, I had only recently ended nearly fourteen years involvement as a political activist in the United States. Concerned about activists' ability to delude themselves into exaggerating their popular influence, I was determined not to spend my time only with people who were engaged in social movements for housing and social services, Christian Base Communities, solidarity movements, or the myriad other issues that occupied the attention of local organizers. But I was well received by the local militantes nonetheless, and I often turned to them for their insights and enthusiasm. The well-known community leader Doña Fili and her family, in particular, have welcomed me whenever I visited, to bring me up to date on local, city, and national affairs, feed me, and provide me with posters and leaflets to share with my students. Though Fili has sometimes seemed disappointed when I neglected to deal with weightier subjects than whether men or women were the ones carrying small children, 
I have learned immeasurably from her over the years about community struggles, political parties, and oppositional organizations. Fili also has very special place in my heart because she was walking with me during the worst moment of my life, when, in 2000, my then five-year-old daughter Maya got hit by a car and broke her leg.

It was my other daughter, Liliana, who provided insight into an issue of political economy dear to Fili's heart that I raised, perhaps not adequately, in the first edition of this book. Using ethnographic examples regarding differences by class with respect to the participation of men in child rearing (chapter 3 ), ${ }^{4}$ and supplementing these with certain insights of the Italian Marxist Antonio Gramsci (1929-35), 5 I tried to reinsert class as a relevant factor in the gender analysis of men and masculinities. It was all captured rather poignantly by Liliana when she and I were riding on a microbus going to see friends who lived in some condominiums that are literally on the other side of the major thoroughfare nicknamed Las Torres. As we boarded the bus, we looked behind us at the self-constructed cinder-block houses we called home during our stays in the neighborhood. But as we disembarked, not five minutes later, and headed across the avenue to the high-rise luxury apartments, Lili remarked, "This street is kind of like the Wood between two worlds." Together we had been reading about children who had found an enchanted way to travel between dissimilar lands in The Magician's Nephew (Lewis 1994), and in her naive vision of our Mexico City world Liliana had captured the profound class schisms that were at once apparent and yet transparent.

\section{OUTING NEIGHBORS AND ANTHROPOLOGISTS}

I have been constantly surprised that I know more people on Huehuetzin Street than many neighbors do. To be sure, I am an outsider in many ways. Yet I am more of an insider, in a real sense, as well. In several ways my periodic presence in the community has become a collective project, as news clippings, tapes of radio shows, flyers, and other items of contemporary Mexico are secured, shelved for safe keeping, and then offered to me to incorporate into articles and books. I have, in this fashion, become a coordinator of local material and a dramatist of events in the colonia. I have become the güero chronicler of Santo Domingosure, the term güero means "light-skinned," but at least it's not the gringo epithet I started with.

Among the traumas and triumphs I have chronicled, there is one I 
have yet to mention. It is documented in a letter written on a piece of white paper that I received shortly after the first edition of the book was published, and it reads:

Dearest Matthew and Michelle

I 6 de Nov 96

It's with a deep sorrow that I inform you

bout the death of my sister Angela

She died on Nov I $3^{\text {th }}$ at nine A.M.

The cause, she had three consecutive

heart attacks and there was nothing

The doctors could do about it.

I know how much she loved you, Michelle

and Liliana, pity she didn't get to meet

Maya. My sister left a great emptiness

May the Lord rest her soul

Yours truly

Hector Jimenez M.

PD Your Room is Available

you are welcome any time ${ }^{6}$

The awful news of the death of my other patron saint, Angela, before she even reached the age of 60 , was confirmation that tragedy can suddenly befall any of us at any time. Remembering her life can just as much remind us of the creativity and determination she showed, as a mother, sister, and wife in her family, and as a compañera and confidante to scores in the south-side neighborhood of Colonia Santo Domingo, where I had the blessed good fortune to spend more than a year with her. ${ }^{7}$

Before she died, Angela saw to it that the plumbing in the bathroom and the kitchen door was fixed. She made sure her daughter Lucha's older son, Ricardo, had his second kidney operation. Before she died, Angela tended to her volatile friend Susana, who again tried to commit suicide with a handful of pills. And, as if she were predicting her own imminent death, earlier, in the fall of 1996, Angela spelled out her wish to be cremated and to have her ashes placed next to those of her grandmother.

Angela passed and I visited as often as I could, usually once or twice a year, and telephoned on the anniversary of her death. When I called in November 2005 to reminisce about Angela and share the news that Michelle and I were divorced, just as with our families in the United States, Angela's daughter, Norma, was saddened but not surprised. She 
had been witness to some of the ups and downs in our marriage over the better part of thirteen years. Over this time, as we developed ethnographic friendships and parts of our lives, like divorce and death, became intertwined, other parts remained distinct-I was always the writer, scribbling down what others had to say.

This book was inspired by many people who seemed to have magnificently contradictory ideas and relationships grounded in gendered and sexual differences. Angela proved an early enigma. She did not work outside the home. She seemed to be a more observant Catholic than her husband, Juan. But she had a presence that was thoroughly at odds with any notion of a submissive or docile woman. She had a grandeur in her bearing, a tongue that could sting and slice to the essence of matters of politics and family, and a moral fiber that became apparent to anyone who had even a short acquaintance with her. When 1996 gave way to 1997, as we each ate one grape for every sound of the chimes on the first New Year's without her, and embraced one another afterward-first with a shake of the right hand, then a hug over the left shoulder, then a pat on the back, and finishing off with another shake of the handHéctor, Norma, the two Miguels, the two Daniels, the two Lidias, the two Dianas, Dalia, and I rejoiced that we carried such vibrant memories of Angela which would remain with us through the rest of our lives.

Soon after Angela died, Juan took up with a younger woman, had a baby with her, and basically moved out of the compound except to store some clothes and to work in Héctor's metal workshop. He and Norma became estranged. Each year I would ask Norma and Miguel if they were still not talking with Juan, and each year they would tell me he had contact with some of Norma's siblings but not with her. Despite the fact they would see each other daily when Juan arrived and left Héctor's workshop, it was not until the end of 2005 that Norma and her father Juan were able to reconcile. Not coincidentally, when I visited at the end of December 2005, Norma had already finished two years of a threeyear program in family counseling, and Héctor had begun referring to her as Dra. López. She told me her dream of working with people from Santo Domingo who have little money but need therapy for couples, for children, or individually. In her kindness and concern for others, she was able to heal the rift with her father, as she also became more like her mother with each passing year.

It seems other things never change in Mexico City. In 2005 the clowns who entertain at infants' birthday parties were still doing their gender shtick: "Who's the boss in the house- ¿Quién manda en la casa?-the 
man or the woman?" And the boys-almost-men were still doing their pullups on the Metro in bicep performances for tweenie girlfriends. Fathers as well as mothers were still distraught when their eighteenyear-old daughters ran off with twenty-six-year-old young men, even when they weren't pregnant- "One only has kids for a certain period," lamented Lupe to me one chilly January evening, resigned to the possibility that he might have just lost his daughter to a young man he wished he trusted more. And Fili and her militant Catholic friends were still protesting against reactionary Church officials and demanding they be replaced by those who were more for el pueblo.

Novelists sometimes explain that they have no idea where their plot and characters will take them-they just follow their impulses to see what will develop by the end of the story. In that sense, an ethnography may be similar to a novel, because the moral of this tale is that there is no predicting how societies and people will change. There is no way to look at culture and guess what the future might hold for social relations and identities, beliefs and behavior. We are all born into cultures, but one's relationship to others in particular cultures, including with respect to class and gender differences, has everything to do with what in this book I term "cultural creativity," as the modus operandi through which people mirror, parrot, question, mold, reject, and change both their consciousness and their relationship to the world. You can exclusively blame machismo for a host of ills among Mexican men (and women). But you can only do this if you wish to be the guardian of facile fairy tales and forfeit any claim to have witnessed actual people living and loving and yearning and wavering and celebrating and failing and laughing their way through their extraordinary lives.

\section{ACKNOWLEDGEMENTS}

Thanks first to my editor, Naomi Schneider, for suggesting this tenth anniversary edition; to my friends, neighbors, and compañeros of Colonia Santo Domingo: you are my observant and enduring guides; to Catherine Lutz, for her enchanted words; to readers whose insights continually revitalize this study; to Brown University for funding my recent visits home to Mexico City; and to Tim and LuzMa for a cozy place to stay.

Providence, Rhode Island April 2006 


\section{NOTES}

I. The Spanish read: "PINCHE MIGUEL CABRÓN HIJO DE TU PINCHE MADRE ...”

2. For a fuller review of Prieur's study, see also Gutmann 2000 .

3. As for prostitutes, after working with men from more rural backgrounds in Oaxaca for several years (see Gutmann, forthcoming), for whom visits to prostitutes were more routine, especially before marriage, I am less concerned that I might have "got it wrong"-I think there are generational, class, and regional rural/urban differences among men that correlate to whether and when they have sexual experiences with prostitutes.

4. Some reviewers of this book have preferred Gilmore's (1990) insistence on the importance of emphasizing commonalities among men within particular societies regardless of class relations, including with respect to fathering.

5. I acknowledge Crehan's point (2002:190) that although Gramsci was given pride of place in this study, more than should have been the case, I "stripped" him of his fundamental narrative of class. See my attempt at a more developed commentary on class in contemporary Mexico in Gutmann (2002).

6. I have wondered why Héctor used English in this letter, because other than silly salutations ("Good morning, Professor!" or "And how are we feeling this evening, Don Héctor?”), we use Spanish with each other. Héctor is nonetheless entirely self-taught, aided by videos of Hollywood movies and technical manuals for his numerous metal lathes and other machines, and he is quite conversant in English. My assumption is that writing in English was a way to distance himself from the acute grief he felt when his sister, who for decades was his kindred soul, suddenly departed this world.

7. The Spanish edition of this book (Gutmann 2000a) appeared after Angela died and was dedicated to her memory. 


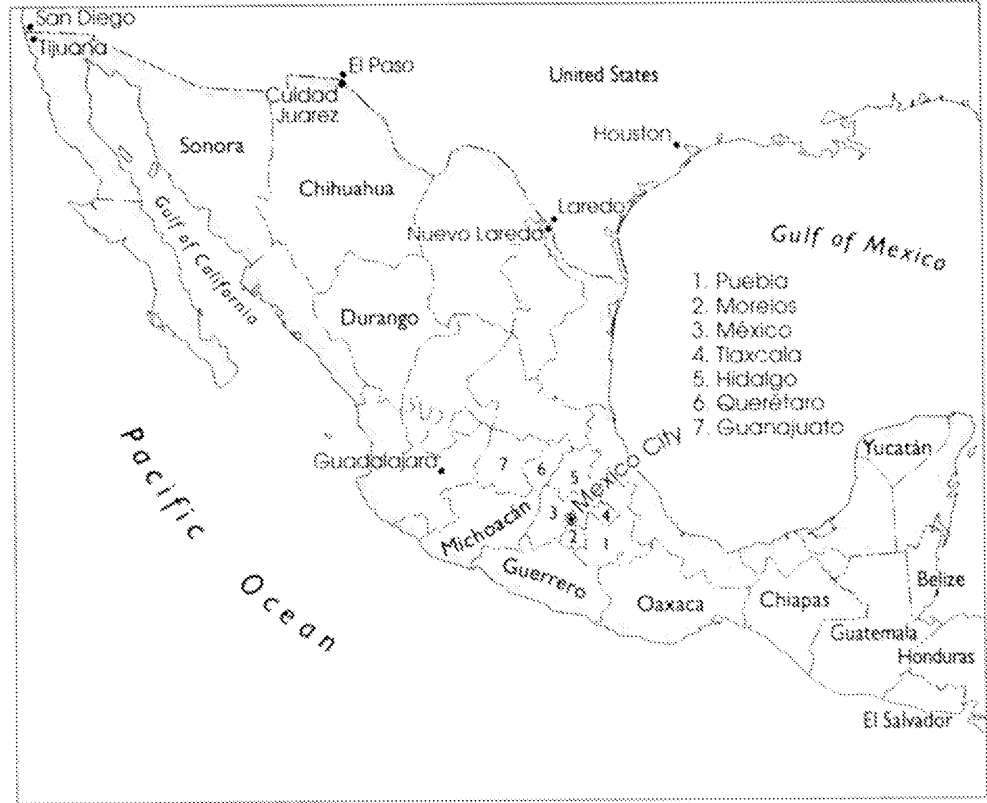

Map I. Mexico 


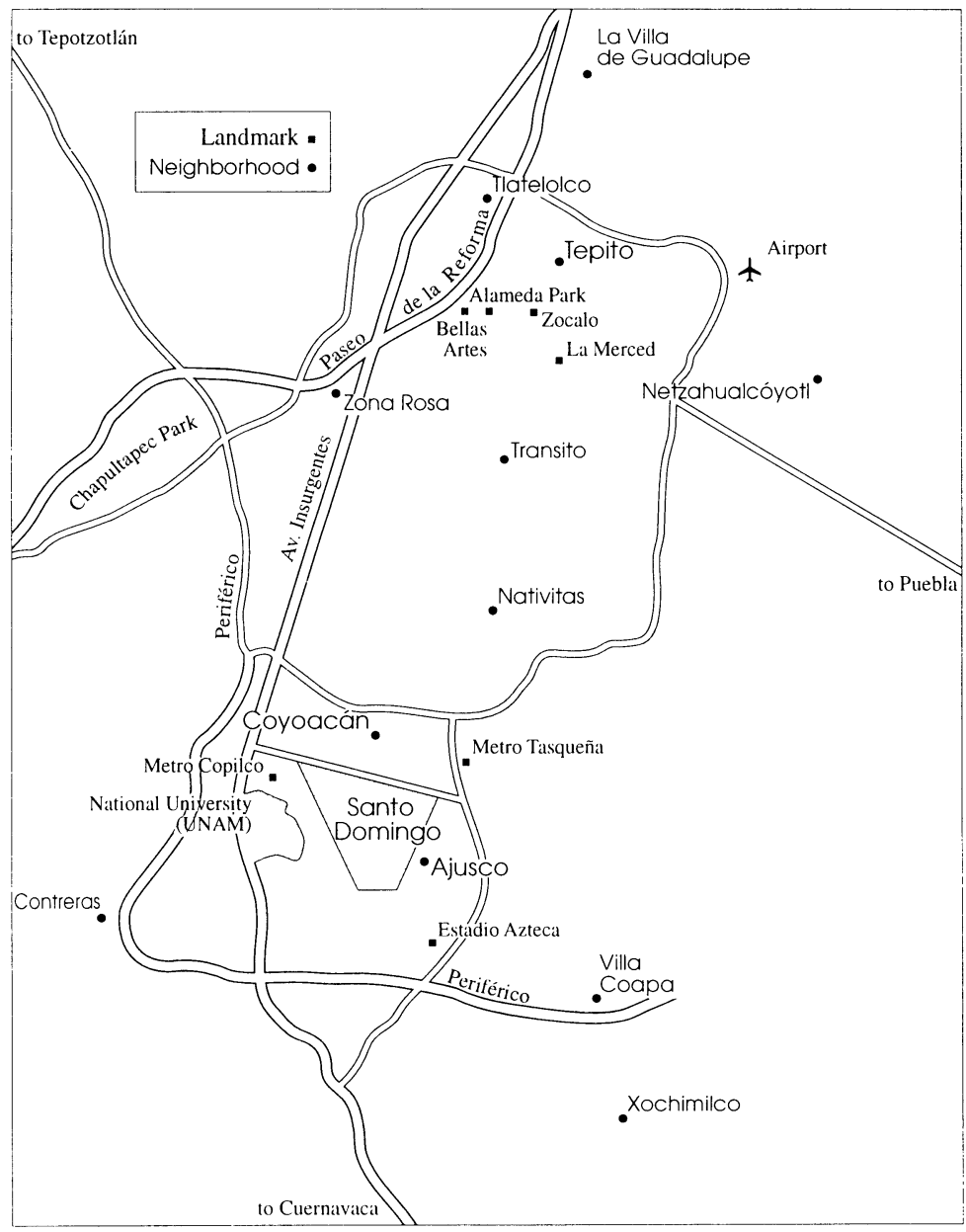

Map 2. Mexico City 